\title{
Quadrinhos, leitura e discurso da interdição em espaços oficiais de educação
}

\author{
Felipe de Souza Costa \\ Universidade de São Paulo (Brasil)
}

\section{Resumo}

Este artigo tem por objetivo analisar as estratégias linguístico-discursivas que legitimaram, em espaços oficiais de educação, a interdição dos quadrinhos como uma prática de leitura. Para tanto, foi selecionado um capítulo do livro "Literatura Infanto-Juvenil", publicado no ano de 1969, para compor o corpus da pesquisa resultante deste artigo. Tal obra fez parte da "Coleção Didática do Brasil", cujos objetivos eram difundir e, de algum modo, prescrever princípios e práticas relativos a diversos temas que envolvessem a educação. De posse desse corpus, orientamo-nos pelas contribuições advindas da análise do discurso de linha francesa, sobretudo tendo como exponentes os estudos de Michel Pêcheux (2009; 2015) acerca de memória e discurso. Guia-nos, neste artigo, a seguinte questão de pesquisa: quais estratégias linguístico-discursivas articulam leitura, quadrinhos e sanção? Finalmente, encontramos as análises que demonstram as seguintes estratégias linguístico-discursivas, com vistas à interdição dos quadrinhos: memória, interdiscurso, argumentação por autoridade, discurso científico e discurso oficial.

Palavras-chave: Análise do discurso. Quadrinhos. Discurso da interdição. Educação.

\section{Comic books, reading and discourse of interdiction in official spaces of education}

\section{Abstract}

IThis article aims to analyze some linguistic-discursive strategies that legitimized, in official spaces of education, the prohibition of comic books as a reading practice. For this purpose, we take a chapter of the book "Youth Literature", published in the year 1969, to compose the corpus of this article. This work was part of the "Didactic Collection of Brazil", whose objectives were to disseminate and, in some way, to prescribe principles and practices related to various themes involving education. In the possession of this corpus, we were guided by the contributions of the discourse analysis of the French line, especially having as examples the studies of Michel Pêcheux (2009; 2015) about memory and discourse. In this article, the following research question guided us: what linguistic-discursive strategies articulate reading, comic books and sanction? Finally, we find the analyzes show that demonstrate the following linguistic-discursive strategies, with a view to the interdiction of the comic books: memory, interdiscourse, argumentation by authority, scientific discourse and official discourse.

Keywords: Discourse analysis. Comic books. Discourse of interdiction. Education. 
Quadrinhos, leitura e discurso da interdição em espaços oficiais de educação

\section{Tiras cómicas, lectura y discurso de la interdicción en espacios oficia- les de educación}

\section{Resumen}

Este artículo tiene por objetivo analizar las estrategias lingüístico-discursivas que legitimaron, en espacios oficiales de educación, la interdicción de las tiras cómicas como una práctica de lectura. Para eso, fue seleccionado un capítulo del libro "Literatura Infantil y Juvenil", publicado en el año 1969, para componer el corpus de la investigación resultante de este artículo. Esta obra forma parte de la "Colección Didáctica de Brasil", cuyos objetivos eran difundir y, de algún modo, prescribir principios y prácticas relativos a diversos temas que involucran la educación. En posesión de ese corpus, nos orientamos por las contribuciones provenientes del análisis del discurso de línea francesa, sobre todo teniendo como exponentes los estudios de Michel Pêcheux (2009; 2015) acerca de memoria y discurso. Nos guía, en este artículo, la siguiente cuestión de investigación: ¿qué estrategias lingüístico-discursivas articulan lectura, tiras cómicas y sanción? Finalmente, encontramos los análisis que demuestran las siguientes estrategias lingüístico-discursivas, con vistas a la interdicción de las tiras cómicas: memoria, inter discurso, argumentación por autoridad, discurso científico y discurso oficial.

Palabras clave: Análisis del discurso. Tiras cómicas. Discurso de la interdicción. Educación.

\section{Primeiras Palavras}

Oexame combina as técnicas da hierarquia que vigia e as da sanção que normaliza. É um controle normalizante, uma vigilância que permite qualificar, classificar e punir (Michel Foucault, 2014).

A epígrafe que abre este artigo destaca da obra de Michel Foucault o exame como um "recurso para o bom adestramento", o qual combina estratégias discursivas visando à vigília e, consequentemente, à norma como resultado de um discurso que interdita ações. Ler é agir sobre um mundo eminentemente atravessado por uma cultura do escrito. Nesse sentido, a leitura de quadrinhos, quer seja em casa ou em espaços escolares formais, sobreviveu em um cenário de clandestinidade durante algum tempo.

Na condição de ilegítimos, a vigilância-patrulha, a que os quadrinhos foram submetidos, faz-nos pensar no controle como um discurso que se ancora em dispersões teórico-semânticas e que (re)/criam cenários de leitura interditados 
pela ação de "exames" sobre esses textos, os quais foram - na história - aplicados por pais, escola, teoria literária e algumas áreas das ciências.

Nestas páginas, analisamos uma seção do livro "Literatura Infantojuvenil", de Antonio D'Ávila, cujo título é "Jornais e Revistas", de 1969, na qual o autor avalia os quadrinhos como objeto de leitura de crianças e adolescentes. Trata-se de uma publicação da Editora do Brasil e é o volume 20 da "Coleção Didática do Brasil". $\bigcirc$ objetivo do livro é analisar e apresentar discussões acerca de conceitos como: leitura, literatura e, sobretudo, literatura infanto-juvenil.

momento político que atravessávamos no Brasil dialogava com um ideário de vigilância político-ideológica que também pairava sobre instituições sociais em que circulavam os textos considerados literários, isto é, a família, a escola, a universidade e a biblioteca. Caracterizado como um "manual" (OLIVEIRA, 2015), o livro cumpre um papel de "orientar" a escolha de textos que se adequem ao que autor denominou como "boa leitura".

Assim, após a leitura do referido capítulo do livro, corpus deste trabalho, guia-nos a seguinte questão de pesquisa: "quais estratégias linguístico-discursivas articulam leitura, quadrinhos e sanção?". Para tanto, utilizamos contribuições teóricas advindas da análise do discurso de orientação francesa, sobretudo a partir de discussões empreendidas por Pêcheux (2009; 2015) e outros propagadores de seus trabalhos. Ademais, também apresentamos contribuições de estudiosos dos quadrinhos a fim de subsidiar as análises que propomos neste artigo.

Por fim, tais análises demonstram que leitura, quadrinhos e sanção são entrelaçados por meio de estratégias discursivas que remontam à memória, ao interdiscurso, à argumentação por autoridade, ao discurso científico e ao discurso oficial. Estratégias discursivas que visam a uma interdição dissimulada de orientação técnica a professores em manual didático produzido por uma editora à época em que o Brasil vivenciava uma ditadura militar. Assim, entendemos que as mesmas estratégias, utilizadas pelo poder estabelecido (tomado) para censurar, são recuperadas para objetar a leitura dos quadrinhos em espaços oficiais de educação. 
Quadrinhos, leitura e discurso da interdição em espaços oficiais de educação

\section{Quadrinhos: uma leitura perigosa}

No texto de Antonio D'Ávila, os quadrinhos são enredados em dois espectros. $O$ primeiro diz respeito ao fato de serem discutidos em um livro que aborda "literatura infanto-juvenil" e o segundo alude que os quadrinhos são, em tese, parte constituinte de uma mídia impressa (jornais e revistas).

O início da seção do livro aponta para uma comparação entre revistas infantis e quadrinhos. Para tanto, o autor do texto recorre à memória a fim de desqualificar os quadrinhos, apresentados como algo novo e, ao mesmo tempo, perigoso. Segundo D'Ávila, trata-se de "grave e sério problema" para as crianças da época, como apresenta no trecho abaixo, intitulado "Memória, ameaça e perigo da leitura dos quadrinhos".

\section{Quadro 1}

\section{Memória, ameaça e perigo da leitura dos quadrinhos}

Do tempo em que líamos o TICO-TICO, a única revista infantil que possuíamos, e de que traçamos neste capítulo pequeno histórico, ao de hoje, quando as cidades do Interior e da Capital estão invadidas pela avalanche de revistas de todos os tamanhos e formatos, num fabuloso número de textos para jovens e crianças, de ambos os sexos, transformou-se completamente o problema da leitura em nosso meio. É que o próprio desenvolvimento da cultura e o das artes gráficas, com - alargamento da obra instrutiva da escola, fizeram aparecer um grave e sério problema, com a ameaça da integridade física, moral e intelectual de nossas gerações novas. Também fisicamente estão ameaçadas, pela má qualidade de certa e conhecida técnica - a do "quadrinho" que, sem dúvida, prejudica, vivamente o sentido visual da criança.

Antonio D'Ávila. Literatura infanto-juvenil. São Paulo: Editora do Brasil, 1969. p. 87.

Como podemos observar, no trecho inicial, o autor se refere à revista infantil Tico-Tico' como algo do passado, provavelmente de sua infância, que passa completamente ilesa de críticas, tendo em vista que era a única a que teve acesso. $\bigcirc$ uso de dêiticos, como em "nós" (presente na desinência de líamos) e em "hoje", revela a necessidade de situar o leitor em uma situação distintiva de tempo: passado (pretérito imperfeito do verbo ler) e o atual, sugerido pelo ano de publicação do livro de D'Ávila, o ano de 1969. Assim, a 
primeira estratégia linguístico-discursiva de que o autor lança mão na intersecção de quadrinhos, leitura e sanção se dá pela memória discursiva:

Concebemos desde então que o fato incontornável da eficácia simbólica ou 'significante' da imagem tenha atravessado o debate como um enigma obsediante, e que, por seu lado, os fatos de discurso, enquanto inscrição material em uma memória discursiva, tenham podido aparecer como uma espécie de problemática reserva. Essa negociação entre o choque de um acontecimento histórico singular e o dispositivo complexo de uma memória poderia bem, com efeito, colocar em jogo a nível crucial uma passagem do visivel ao nomeado, na qual a imagem seria um operador de memória social, comportando no interior dela mesma um programa de leitura, um percurso escrito discursivamente em outro lugar: tocamos aqui o efeito de repetição e de reconhecimento que faz da imagem como a recitação de um mito (PÊECHEUX, 2015, p. 45, grifo do autor).

Aproveitando as discussões de Pêcheux (2015), podemos pensar no dêitico "hoje" como uma instância do visível e a materialidade linguística do texto de D'Ávila, a respeito dos quadrinhos, no âmbito do nomeado. Temos, então, uma imbricação entre memória discursiva e memória social como pontos indissociáveis. No quadro a seguir, elaboramos uma coluna com vários acontecimentos históricos que circundavam a produção de D'Ávila, que foi estrategicamente destaca na coluna à direita: 
Quadrinhos, leitura e discurso da interdição em espaços oficiais de educação

\section{Quadro 2}

Memória social, memória discursiva e materialidade linguística

\begin{tabular}{|c|c|}
\hline "Visível" - hoje (1969) & "Nomeado" - texto de D'Ávila \\
\hline $\begin{array}{l}\text { Surgimento de } O \text { Pasquim, em } 26 \text { de ju- } \\
\text { nho de } 1969 \text {. Exílio de diversos artistas, } \\
\text { como Caetano Veloso e Gilberto Gil. }\end{array}$ & $\begin{array}{l}\text { "Interior e da Capital estão invadidas pela } \\
\text { avalanche de revistas de todos os tama- } \\
\text { nhos e formatos [...]". }\end{array}$ \\
\hline $\begin{array}{l}\text { Ato Institucional no } 6 \text {, de } 1^{\circ} \text { de fevereiro } \\
\text { de } 1969 \text { - concedia mais poderes aos } \\
\text { militares. }\end{array}$ & $\begin{array}{l}\text { "[...] fabuloso número de textos para jo- } \\
\text { vens e crianças, de ambos os sexos }[\ldots] " .\end{array}$ \\
\hline $\begin{array}{l}\text { Ato Institucional no 7, de } 26 \text { de fevereiro } \\
\text { de } 1969 \text { - suspensão das eleições. }\end{array}$ & $\begin{array}{l}\text { "[...] ameaça da integridade física, moral } \\
\text { e intelectual de nossas gerações novas }\end{array}$ \\
\hline $\begin{array}{l}\text { Ato Institucional no 15, de } 11 \text { de setembro } \\
\text { de } 1969 \text { - censura à imprensa. }\end{array}$ & \\
\hline $\begin{array}{l}\text { Decreto-Lei n }{ }^{\circ} 898 \text {, de } 29 \text { de setembro de } \\
1969 \text {-definia os crimes contra a seguran- } \\
\text { ça nacional, a ordem política e social. } \\
\text { Estabelecia seu processo e julgamento e } \\
\text { dava outras providências. }\end{array}$ & $\begin{array}{l}\text { "[...] estão ameaçadas, pela má qualida- } \\
\text { de de certa e conhecida técnica - a do } \\
\text { 'quadrinho' que, sem dúvida, prejudica } \\
\text { vivamente o sentido visual da criança". }\end{array}$ \\
\hline $\begin{array}{l}\text { Assassinato de Carlos Marighella, em } 4 \\
\text { de novembro de } 1969 .\end{array}$ & \\
\hline $\begin{array}{l}\text { Decreto Lei n }{ }^{\circ} 1.072 \text {, de } 30 \text { de dezembro } \\
\text { de } 1969 \text { - guardas civis são integrados } \\
\text { à Polícia Militar, para a "manutenção da } \\
\text { ordem pública e do poder". }\end{array}$ & \\
\hline
\end{tabular}

No Quadro 2, recuperamos alguns acontecimentos históricos que se coadunam ao ano de publicação do livro de Antonio D'Ávila e que, ao mesmo tempo, indiciam os influxos de interdição e de sanção no texto escrito e, sobretudo, no combate à linguagem dos quadrinhos. Essa, por sua vez, era contraposta a um número incontável de publicações "estranhas" e distantes do modelo de boa leitura, que era dado pela existência perene e nostálgica da revista Tico-Tico. A revista, possivelmente exclusiva para crianças "sexo masculino", também representava um perigo para o gênero feminino, já que havia 
outras leituras além da Tico-Tico, única para o público infantil. A "avalanche de revistas de todos os tamanhos e formatos" é duramente criticada, uma vez que o aumento numérico de publicações rompe com o monopólio da Revista TicoTico e, por conseguinte, torna mais difícil o controle, encarado como sinônimo de qualidade.

Nesse cenário de interdição, a memória discursiva também atua no sentido de remeter-nos a um passado mais distante de história da leitura, uma vez que os quadrinhos representavam uma leitura perigosa. De acordo com Briggs e Burke (2004), que estudaram as mídias a partir da sociedade, o processo de leitura como comercialização passou por cinco grandes momentos: leitura crítica, leitura perigosa, leitura criativa, leitura extensiva e leitura privada. Ao falar da leitura perigosa, os autores afirmam:

Os perigos da leitura privada eram frequentemente discutidos. Agindo ou não como tranquilizante, a atividade era vista como perigosa, especialmente quando praticada por grupos subordinados, como mulheres e 'gente comum' [...]. Em Veneza, no fim do século XVI, por exemplo, um trabalhador do ramo da seda foi denunciado à lnquisição porque lê o tempo todo, e um ferreiro de espadas, porque 'fica acordado a noite inteira lendo' (BRIGGS; BURKE, 2004, p. 70).

fato de a leitura dos quadrinhos, supostamente, ameaçar a integridade física, moral e intelectual das crianças demonstra que o perigo não está apenas no ato de ler, mas no aspecto de subversão que a atividade pode sugerir. Subverte-se, portanto, uma ordem instituída, geralmente, por quem detém o poder los militares, juntamente com os civis que compartiam da mesma posição, em 1969, e a lgreja Católica, na ldade Média). Sob a égide da vigilância e do exame, de um lado ou de outro e em tempos distintos, a continuidade de uma prática medieval denuncia que buscam interditar ações subjetivas, a diversidade e, por consequência, a liberdade.

Não raro, a partir desse modus operandi recorre-se a práticas discursivas nostálgicas para legitimar e desprestigiar o novo, reclamando um passado: "no meu tempo...", "antigamente...", "quando eu era criança..." etc. Assim, investe-se na criação de uma "[...] repetição e de reconhecimento que faz da imagem como a recitação de um mito" (PÊCHEUX, 2015, p. 45). Nesse sentido, o mito renasce de um suposto passado inebriante que reacende estratégias 
Quadrinhos, leitura e discurso da interdição em espaços oficiais de educação

mnemônicas e faz erigir, no presente, discursos que classificam o "novo" como perigoso, subversivo e ameaçador. Nessa classificação hierárquica, coloca-se o passado mítico como bom modelo, que mereceria perpetuação e continuidade.

Nessa direção, podemos depreender que a periculosidade de uma leitura é determinada na intersecção entre sociedade, poderes instituídos e busca de uma classificação binária que afere prescrições entre o bem e o mal. Trata-se, de algum modo, de uma estratégia maniqueísta, que, em geral, é assinada por pessoas que gozam de certa autoridade para (des)legitimar esta ou aquela leitura como boa ou má. Em face disso, Antonio D'Ávila convoca alguns especialistas para dar crédito à sua sanção, valendo-se de um argumento de autoridade.

\section{Quadro 3}

\section{Argumento de autoridade: somando forças à interdição}

Em diversos capítulos deste livro estudamos o problema, resumindo críticas, censuras e advertências e campanhas contra a má leitura da criança e do adolescente. Verdadeiro programa educacional esse, tem arrolado mestres, psicólogos, educadores, autoridades da justiça e da administração pública, tem reunido sacerdotes, juízes e pais no estudo e no planejamento de campanhas de encontro aos efeitos da má leitura. Documento de grande expressão é o que reproduzimos na íntegra, com referência às revistas infanto-juvenis "Revistas de Quadrinhos".

D'Ávila, Antonio. Literatura infanto-juvenil. São Paulo: Editora do Brasil, 1969. p. 87

Nesse excerto do manual para professores, D'Ávila enaltece um documento de "grande expressão" que afirma ser reproduzido integralmente em seu livro. $O$ documento a que o autor se refere é um parecer que versava sobre quadrinhos e que foi elaborado por uma comissão instituída pelo então secretário de Educação e Cultura da Prefeitura de São Paulo, João Accioly. Analisaremos esse parecer mais adiante.

Por ora, atentemo-nos aos nomes que foram convocados para somar força à sanção que D'Ávila propunha à linguagem dos quadrinhos. Neste momento, todos foram citados pelos papéis sociais que ocupavam, não nominalmente. Ao final, alguns nomes assinam o parecer. Essa convocação, seja de nomes ou de papéis exercidos socialmente, faz alusão a uma estratégia linguístico-discursiva ligada ao ato de argumentar. Visando à legitimação de 
seu posicionamento a respeito dos quadrinhos, o autor recorre a outros especialistas com o objetivo de criar uma imagem de si mais modesta e, ao mesmo tempo, evita o solipsismo de seu posicionamento. De acordo com Fiorin (2015), o argumento de autoridade pode ser discutido a partir de:

[...] dois tipos de autoridade a que se pode recorrer: a da ordem do saber (o perito ou especialista) e a do domínio do poder (aquele que exerce comando sobre outros). Em geral, a segunda categoria é vista com muito maior desconfiança, sendo alvo de ironias (por exemplo, o chefe tem sempre razão; o chefe não erra, quando muito se engana). Nada há de errado em recorrer à opinião de um especialista. Isso ocorre no discurso científico, nos procedimentos judiciários e mesmo em nossa vida cotidiana. No entanto, é preciso ficar claro que o ponto de vista de uma autoridade, a menos que seja acompanhado de outras provas, é um argumento plausível, mas não necessariamente verdadeiro (FIORIN, 2015, p. 176).

Sabendo que o argumento de autoridade, embora válido como estratégia argumentativa, precisa ser tomado com algum cuidado. Diante disso, resta-nos perguntar: por onde andavam os especialistas com pensamentos diversos dos signatários do parecer, que não foram convocados para compor a comissão? Certamente, não teremos respostas para essa pergunta, mas convém lembrar que os leitores de tais revistas, consideradas como más leituras, não foram escutados, mas excluídos, diante de um discurso que congregou especialistas uníssonos.

Isso nos leva a pensar que, a partir da separação exposta por Fiorin (2005), o alto grau de especialidade, atribuída ao argumento de autoridade, pode ser utilizado para, em vez de somar, subtrair. Nesse sentido, saber também é uma forma de poder, sem que o poder fique restrito aos cargos instituídos pelo Estado. Pensando nisso, no quadro 4, distribuímos os papéis sociais citados por D'Ávila, a partir da categoria de discurso de autoridade sugerida por Fiorin (2015). Observe a divisão de autoridades citadas: 
Quadrinhos, leitura e discurso da interdição em espaços oficiais de educação

\section{Quadro 4}

Âmbitos do discurso de autoridade

\begin{tabular}{|l|l|}
\hline \multicolumn{1}{|c|}{ Ordem do saber } & \multicolumn{1}{c|}{ Domínio do poder } \\
\hline Mestres & Autoridades da justiça \\
\hline Psicólogos & Autoridades da administração pública \\
\hline Educadores & Sacerdotes \\
\hline Pais & Juízes \\
\hline
\end{tabular}

Em igual número, a comissão parecia, portanto, reunir vozes supostamente distintas sobre o mesmo assunto, mas, na verdade, o resultado do parecer demonstra uma visão unilateral acercado assunto e que, como era de esperar, se coaduna à do autor do texto em análise. Dessa maneira, a estratégia linguístico-discursiva que tenciona os quadrinhos no rol de uma leitura perigosa também pode ser elucidada pelo uso do argumentum ad verecundiam (argumento de autoridade). Além disso, é possível, ainda, perceber uma aproximação do uso desse tipo de argumento sob o viés de um discurso científico, que, conforme explicita Pêcheux (2009), visa à dissimulação. Nesse sentido, o 10 autor alerta-nos:

[...] o próprio de toda formação discursiva é dissimular, na transparência do sentido que nela se forma, a objetividade material contraditória do interdiscurso, que determina essa formação discursiva como tal, objetividade material essa que reside no fato que 'algo fala' (ça parle) sempre "antes, em outro lugar e independentemente", isto é, sob a dominação do complexo das formações ideológicas. Descobrimos, assim, que os dois tipos de discrepância, respectivamente, o efeito encadeamento do pré-construído e o efeito que chamamos de articulação - que consideramos, de início, como leis psicológicas do pensamento - são, na realidade, determinados materialmente na própria estrutura do interdiscurso (PÊCHEUX, 2009, p. 149, grifo do autor).

Como vemos, o efeito de articulação, utilizado no texto de D'Ávila, cumpre - à margem da memória discursiva - um interdiscurso com vistas a uma sanção dos quadrinhos. Subsidiada por dois movimentos linguístico-discursivos, a memória discursiva e o recrutamento de especialistas, o texto em análise situa a leitura de quadrinhos no bojo de uma periculosidade que, a exemplo dos 
subversivos ao regime militar, precisa ser "[...] (des)qualificada, classificada e punida" (FOUCAULT, 2014, p. 181).

Finalmente, adjacente à memória e ao argumento de autoridade, a leitura de quadrinhos poderia ser perigosa, segundo D'Ávila, porque, inebriados por um discurso oriundo de um psiquiatra, o cientificismo ganhou mais força rumo à interdição dessa linguagem junto às crianças. Até agora, vimos que os quadrinhos representariam perigo, porque, primeiramente, não se comparam às ofertas de leitura do passado. Em segundo lugar, porque subvertem a ordem pré-estabelecida e, finalmente, porque uma nuvem de especialistas atesta sua má qualidade. Mas os conteúdos que os quadrinhos veiculam também podem ser perigosos.

\section{Quadro 5}

\section{Os conteúdos do perigo}

Quanto aos demais perigos não é preciso encarecê-los: aí temos a literatura policial para crianças, de crimes e de mortes, as famosas detetives, as cenas de banditismo de far-west, os textos de um maravilhoso falso e deturpador de inteligências, páginas de sugestão ao crime e à violência e uma série de atentados à integridade espiritual e sentimental de nossa criança e de nosso jovem.

D'Ávila, Antonio. Literatura infanto-juvenil. São Paulo: Editora do Brasil, 1969. p. 87

Os temas recriminados e mencionados por D'Ávila são aqueles que, à época, começavam a pulular em textos de ficção, mas não eram novidades, haja vista que outros livros da literatura, supostamente consagrada, já haviam recorrido a muitos deles para compor suas narrativas. No entanto, o combate a esses temas, com mais ênfase, se deu a partir de um estudo denominado "A sedução dos inocentes", de Frederic Wertham. Os temas que D'Ávila critica já haviam sido objeto de discussão pelo psiquiatra e, em adição, pelos que assinaram o parecer mencionado no texto em análise. Segundo Rama e Vergueiro (2004),

Wertham reuniu suas observações em um livro denominado A sedução dos inocentes, publicado em 1954, que foi um grande sucesso de público e marcou, durante as décadas seguintes, a visão dominante sobre os quadrinhos nos Estados Unidos e, por extensão, em grande parte do mundo. Entre outras teses, o livro defendia, por exemplo, que a leitura das histórias do Batman poderia levar os leitores ao homossexualismo, na medida em que esse herói e seu 
Quadrinhos, leitura e discurso da interdição em espaços oficiais de educação

companheiro Robin representavam o sonho de dois homossexuais vivendo juntos. Ou que o contato prolongado com as histórias do Superman poderia levar uma criança a se atirar pela janela de seu apartamento, buscando imitar o herói (RAMA; VERGUEIRO, 2004, p. 121.

livro de Wertham, produzido no período pós Segunda Guerra Mundial, reúne elementos de uma sociedade que, aterrorizada por um senso de combate a ideologias "progressistas" (WERTHAM, 1954, p. 175), procura rechaçar toda e qualquer produção que pudesse suscitar ideias "estranhas" à ordem de comportamento estabelecida. É, nesse sentido, que D'Ávila pode ter alertado os leitores de seu texto para "[...] atentados à integridade espiritual e sentimental de nossa criança e de nosso jovem".

Em relação ao "sentimental" e ao "espiritual", é fato que, embora não mencionada, a homossexualidade e outras formas de "exposição sexual" deveriam também ser combatidas, uma vez que, para o psiquiatra: "Os quadrinhos estimulam as crianças sexualmente. Esse é um fato elementar da minha pesquisa. Nos quadrinhos, repetidas vezes, em fotos, textos e nos anúncios, também, chama-se atenção para características sexuais e ações sexuais" 12 (WERTHAM, 1954, p. 175, versão nossa).

Os demais conteúdos, denunciados por D'Ávila, se coadunam àqueles objetados por Wertham: criminalidade, delinquência e homicídios. Trata-se, na verdade, de um combate a algo que está na gênese na história da humanidade, mas que, segundo os censores, não deveria ser tratado em ficção, sobretudo em quadrinhos.

Assim sendo, chegamos à última das estratégias linguístico-discursivas, identificadas por D'Ávila como uma maneira de manter efeitos de sentido de uma leitura perigosa: o discurso científico como verdade inquestionável. Essa utilização, no entanto, é feita de modo muito diferente do argumento de autoridade, uma vez que o autor das ideias repetidas por D'Ávila não foi nominalmente mencionado (Wertham). Os influxos de sua pesquisa são tratados a partir de um investimento na recuperação do discurso científico que, em voga, não poderia ser questionado. Acerca desse modus operandi de tratativa dissimulada em argumentação, Osakabe alerta-nos:

O estudo da organização argumentativa de um discurso depende totalmente das considerações feitas anteriormente sobre as 
condições de produção. Isto é, depende das imagens mútuas que se pressupõem fazer locutor e ouvinte; depende das imagens que pressupõem fazer locutor e ouvinte sobre o referente; depende, em último lugar, dos atos de linguagem que o locutor realiza no momento do discurso. E, na medida do possível, tentar-se-á evitar repetir o que foi dito, só o fazendo nas ocasiões em que a repetição se fizer imprescindível para a clareza (OSAKABE, 1999, p. 109).

Portanto, as seguintes estratégias linguístico-discursivas trabalham juntas na proposição de um ideário de ameaça, medo e periculosidade por parte dos quadrinhos: a memória discursiva, o discurso de autoridade e o discurso científico, circulante como única verdade. É importante ressaltar que os estudos de Wertham foram duramente criticados, uma vez que a metodologia empregada era extremamente frágil. Os informantes da pesquisa foram escolhidos a dedo, o que nos permite, em primeiro lugar, questionar o rigor científico de seu trabalho e, por consequência, protestar o lugar de única verdade que um discurso científico convoca para si.

\section{Quadrinhos: uma leitura ilícita}

A ilicitude dos quadrinhos só poderia ser atestada por meio de um discurso oficial, resultado de todo esse tensionamento entre medo, perigo e sanção. Lembremos o momento sócio histórico da publicação do livro em análise, isto é, o ano de 1969 e tudo o que acontecia no Brasil. Os Atos Institucionais, Decretos e Atos Complementares eram utilizados à exaustão como expressão do poder estabelecido. A exemplo do que acontecia nesse espaço maior, as "microssociedades" - entendendo-as aqui como instituições formais do Estado - também se espelharam nesse paradigma para dirimir questões concernentes aos seus respectivos funcionamentos.

Lembremos que, na teoria marxista, o aparelho de Estado (AE) compreende: o governo, a administração, o exército, a polícia, os tribunais, as prisões etc., que constituem o que chamaremos, a partir de agora, de aparelho repressivo do Estado. Repressivo indica que o aparelho de Estado em questão "funciona através da violência" - ao menos em situação limites (pois a repressão administrativa, por exemplo, pode revestir-se de formas físicas) (ALTHUSSER, 1985. p. 67-68). 
Quadrinhos, leitura e discurso da interdição em espaços oficiais de educação

Nesse sentido, escolas, universidades e bibliotecas também eram, de algum modo, bombardeadas por aparatos legais que dirigiram e organizavam suas atividades. O parecer, emitido pela comissão à Secretaria de Educação e Cultura do Município de São Paulo, é um exemplo dessa verborragia legalista que assolava sobremaneira as instituições estatais. Reproduzido na íntegra no livro de D'Ávila, analisaremos apenas os "considerandos" existentes em tal documento, os quais dizem respeito unicamente às "revistas em quadrinhos".

\section{Quadro 6}

\section{Ilicitude dos quadrinhos - uma ameaça à leitura de textos escritos}

- que a civilização multissecular da escrita se acha em perigo, conforme denunciou recente Tristão de Ataíde, ameaçada de desaparecimento, em virtude da ação solapadora de modernos processos de divulgação, quais sejam: o rádio, o cinema, a televisão e, por fim, as atuais revistas infanto-juvenis, que objetivam transmitir ao indivíduo toda a gama de sensações estéticas e encantamento espiritual através da visão e da audição em prejuízo da leitura.

- que está positivada em nossas crianças e em nossos jovens, a "preguiça da leitura", como consequência do vício por eles adquirido com o compulsar de tais revistas.

- que tem resultado da "preguiça da leitura", "a preguiça de estudar", por isso que, para estudar, é necessário "ler" e eles se acham habituados unicamente a "ver" (o cinema, a televisão, a revista em quadrinhos, e a "ouvir" o rádio) dimanando daí o desmoralizante espetáculo das reprovações em massa que anualmente se registram em nossas escolas.

- [...] as revistas e demais publicações destinadas à infância e à juventude deverão apresentar as seguintes proporções em suas páginas de contos e histórias - o mínimo de $20 \%$ de texto corrido para as revistas infantis, sendo $40 \%$ o mínimo de texto corrido para as revistas juvenis.

D'Ávila, Antonio. Literatura infanto-juvenil. São Paulo: Editora do Brasil, 1969. p. 88 e 91 .

No quadro 6, a lista de perigos e ameaças é ampliada. Vale lembrar que, na condição de discurso citado, o parecer amplia e detalha o que o texto de D'Ávila apresentava em linhas gerais. Em que pese o fato de o documento fazer parte elogiosamente de seu livro, D'Ávila divide o peso da sanção com pares que têm o mesmo posicionamento que o seu. Além disso, corrobora com argumentos que colocam os quadrinhos como grande vilão de uma cultura "multissecular" da língua escrita. 
Para a Comissão e, adicionalmente, para D'Ávila, o ato de ler deve se restringir à apropriação do sistema de escrita alfabético ou, em outras palavras, à decodificação. Tudo o que estiver fora de letras, palavras ou frases não pode ser lido. A causa para problemas de leitura e escrita, pelos quais a educação do Brasil ainda é duramente atacada pela mídia atual, estaria na coexistência de outras modalidades de uso da língua e da linguagem. À época, representavam ameaças à leitura e à escrita: "o rádio, o cinema, a televisão e, por fim, as atuais revistas infanto-juvenis". A justificativa para tal ameaça se dá no campo do combate à sinestesia. Cruzar sensações é um crime e, por isso, ler deveria implicar, para os componentes da comissão, em silêncio, concentração e visualidade. Note-se que o ato de pensar e refletir estariam excluídos desse processo.

Essa sanção às mídias, grande novidade da época, faz-nos pensar como, de tempos em tempos, há sempre algo que a escola, como um aparelho ideológico do Estado, precisa combater para manter-se irredutivelmente fincada em um tradicionalismo mítico e fantasioso. Ao referirmo-nos ao tradicionalismo como forma de irredutibilidade, falamos de algo que mata qualquer processo inventivo, em que pese o fato de a escola ser um espaço tradicional. Nesse sentido, é preciso lembrar que, mesmo as tecnologias que favoreceram um desempenho melhor da língua escrita, já passaram por achaque parecido, como o que foi enunciado no primeiro "considerando" do parecer. Sobre essa resistência a novas tecnologias, Ferreiro relembra que

[...] essa mesma instituição [escola] reagiu com forte rejeição ao aparecimento do avanço tecnológico seguinte: a esferográfica, instrumento de escrita que trazia a tinta incorporada, evitando, portanto, o gesto arriscado de ir do tinteiro ao papel que, de fato, tornava inútil o buraco deixado nas carteiras para o famoso tinteiro e que, como acréscimo, substituía a ponta afiada da pena metálica (muitas vezes instrumento de agressão) por uma ponta arredondada. Diante destas vantagens a escola-instituição reagiu com um $N \tilde{O} O$ rotundo, usando argumentos que hoje soam ridículos, como o de que no novo instrumento (caneta esferográfica) ia "arruinar a letra" dos estudantes [...]. A instituição escolar frequentemente aposta em batalhas perdidas de antemão, mas o faz com o propósito de manter 'suas próprias tecnologias' (FERREIRO, 2013, p. 455-456, grifo do autor). 
Quadrinhos, leitura e discurso da interdição em espaços oficiais de educação

Além disso, com o aparecimento da máquina de datilografar, ainda de acordo com Ferreiro (2013), a escola saiu em defesa da caneta esferográfica, pois esse aparelho poderia deixar os estudantes menos atenciosos e mais preguiçosos. Como se pode observar, a objeção à preguiça e ao vício, explicitada no segundo "considerando" do parecer, remonta um discurso religioso cristão que justapõem "preguiça e vício" como algo que deve ser combatido, sobretudo para crianças que, no futuro, deverão (sobre)viver de seu trabalho.

A história é um imenso sistema natural-humano em movimento, cujo motor é a luta de classes. Portanto, a história, ainda uma vez, isto é, a história da luta de classes, isto é a reprodução/transformação das relações de classes - com os caracteres infraestruturais leconômicos) e superestruturais (jurídico-políticos e ideológicos) que lhes correspondem (PÊCHEUX, 2009, p. 138).

Ler textos com imagens, assistir à televisão ou escutar rádios seriam atividades que, nessa visão, representariam a manutenção da preguiça que, ainda na mesma visão, há tempos vem "assolando" a humanidade.

Como ápice de valorização da cultura da escrita e combate ao texto visual, o parecer determina, em porcentagem, uma quantidade para cada faixa etária, visando a evitar esse processo desidioso que tem origem nas imagens, consideradas como meio de facilitação de acesso a língua escrita. Essa necessidade de negação de coexistência de demais modalidades da língua e da linguagem transforma-se, de alguma forma, no nascedouro da supervalorização da modalidade escrita, a qual, ainda nos dias atuais, parece subsistir.

Há algum tempo, tem havido, na cultura ocidental, uma clara preferência pela monomodalidade. Os gêneros mais valiosos da escrita |romances literários, tratados acadêmicos, documentos e relatórios oficiais etc.) não tinham ilustração, e tinham graficamente uniformes e densas páginas impressas. As pinturas, quase todas, usavam o mesmo suporte (tela) e o mesmo meio (óleos), qualquer que fosse o seu estilo ou assunto. Em apresentações de concerto todos os músicos vestidos de forma idêntica e só ao condutor e aos solistas foi permitido um mínimo de expressão corporal. As disciplinas especializadas teóricas e críticas que se desenvolveram para falar dessas artes tornaram-se igualmente monomodais: uma linguagem para falar de língua/linguagem (linguística), outra para falar de arte (história da arte), outra para falar de música (musicologia), e assim por diante. Cada um com seus próprios métodos, suas próprias 
suposições, seu próprio vocabulário técnico, suas próprias forças e seus próprios pontos cegos (KRESS; VAN LEEUWEN, 2001, p. 12, versão nossa).

Os quadrinhos, multimodais por natureza (RAMOS, 2012), perseguiam uma direção unilateral em busca da manutenção de algo que representasse o "mono" e, na sociedade da época, eram sinônimo de perigos associados às pessoas que prezavam por uma pluralidade de ideias, concepções e ações. Na ditadura, a monomodalidade era perseguida e utilizada como forma de objetar qualquer subversão a essa ordem. Textos como o do D'Ávila e o do parecer, refletem e refratam tais ideais, tomando a linguagem dos quadrinhos indesejável, desordeira e ameaçadora para as crianças.

Em sua forma mais comum, a teoria liberal em educação privilegia uma concepção de experiência que é equacionada como "o atendimento das necessidades das crianças" ou como o desenvolvimento de relações cordiais com os estudantes, de tal maneira a ser possível manter ordem e controle na escola (GIROUX, 1988, p. 70).

Nesse sentido, se subvertem tantas ordens preestabelecidas, inclusive o caráter "multissecular da escrita". Não basta combater, é preciso criar mecanismos que reprimam a "proliferação" de tais subversões. Cumprem esse papel, portanto, o texto de D'Ávila (manual) e o parecer retomado em seu livro, conferindo, portanto, aos autores um caráter de "legislador", que, com vistas à manutenção da ordem, podem censurar o que thes parecer desviante. Nasce daí a estratégia linguístico-discursiva que se traveste de aparato legal (parecer ou manuall para interditar a leitura de quadrinhos.

\section{Quadro 7}

\section{$O$ veredito dos quadrinhos}

Propõe ao sr. Secretário de Educação e Cultura da Prefeitura Municipal de S. Paulo:

a) seja severamente proibido o ingresso de revistas desenhadas "em quadrinhos", em virtude de seu caráter marcadamente anti-pedagógico, nos Parques Infantis e Bibliotecas do Município.

D’Ávila, Antonio. Literatura infanto-juvenil. São Paulo: Editora do Brasil, 1969. p. 88. 
Quadrinhos, leitura e discurso da interdição em espaços oficiais de educação

A proibição em forma de parecer é o resultado de inúmeras desqualificações por que passou a linguagem dos quadrinhos nos diversos "considerandos" que tratavam do âmbito educativo. $\bigcirc$ ingresso de tais revistas também devia ser combatido porque não estaria alinhado ao ideário político-social em que o texto (manual) foi publicado. Em outras palavras, as aspirações fundamentalistas que subjaziam a manutenção temática da ditadura militar estão expressas no parecer com o objetivo de rechaçar os quadrinhos e, ao mesmo tempo, de colocá-lo em conflito com a "ordem estabelecida" no âmbito nacional.

\section{Quadro 8}

\section{Quadrinhos versus fundamentos da Ditadura no Brasil}

- que a generalização das revistas de "história de quadrinhos" vem redundando em grave e perigoso ônus para o rebaixamento do nível de ensino, tanto primário como ginasial, cada vez mais afasta os nossos jovens dos princípios fundamentais da educação cívica moral e espiritual da família brasileira.

D’Ávila, Antonio. Literatura infanto-juvenil. São Paulo: Editora do Brasil, 1969. p. 88.

Finalmente, os quadrinhos, além de protagonizar diversas ameaças à instituição da escola, também bravateavam contra a "ordem nacional" alardeada no período militar. Os princípios, duramente atacados, estavam concentrados, mais uma vez, na base constituinte de uma política jactante da ditadura: "educação cívica moral e espiritual" e, por incrível que possa parecer incrivelmente, a "família brasileira". Supostamente, ao atacar essa "estrutura basilar", os quadrinhos passaram a ser considerados subversivos e, portanto, sujeitos a toda e qualquer interdição, pois representavam perigo, subversão, atentado, sinestesia, diversidade, delinquência, homicídio, crime e ilicitude. Esse campo semântico, portanto, resvala em uma imagem construída a muitas mãos pelo autor de um manual destinado a professores e por signatários-especialistas de um parecer que prefigura como discurso oficial no município de São Paulo. 


\section{Considerações (quase) finais}

discurso da interdição, no que diz respeito à leitura, tem sido utilizado a fim de contemporizar a favor de supostos "grandes problemas" nacionais que assolam a população com os mais perigosos desvios "progressistas", que se opõem a um ideário de conservadorismo. Os inimigos são, quase sempre, os mesmos: a leitura, os livros, a escola, os professores, a "novidade", os quais, via de regra, intentam contra a moral e a família brasileira.

Os quadrinhos, como pudemos verificar ao longo deste artigo, trazem consigo a interdição como traço identitário de sua constituição. Mesmo nos dias atuais, a leitura de quadrinhos parece denotar certo desprestígio por parte da instituição-escola, apesar de sua alta adesão por parte dos leitores - alunos que frequentam espaços escolares. No máximo, conforme explicita Ramos (2012), os quadrinhos são considerados algo destinado apenas para criança e que não serve à aprendizagem de uma leitura mais canônica, isto é, aquela que acontece integralmente por meio da língua escrita - resquício de um discurso hierarquizante.

Diante de tais constatações, entendemos que as estratégias utilizadas por Antonio d'Ávila, no livro Literatura Infanto-Juvenil, de 1969, articulam leitura, quadrinhos e sanção por meio dos seguintes estratagemas linguístico-discursivos: um jogo mnemônico que escolhe o passado como o tempo-lugar do bom-modelo, negando qualquer possibilidade de rompimento com um tradicionalismo excludente e conservador; o uso de argumento de autoridade, que convoca especialistas com posicionamentos unidirecionais para ratificar teses iguais à do autor do texto em análise; o investimento na dissimulação (PÊCHEUX, 2009), que investe na apropriação do discurso científico para legitimar objeção; e, por fim, a produção de textos que se assemelham aos que circulam nas instâncias legalmente instituídas (parecer e manual), mantendo diálogo direto com discursos oficiais da época de suas veiculações.

Finalmente, as análises deste artigo, além de abrirem espaços para outras discussões e leituras do corpus, também podem ajudar a compreender os recentes movimentos em que o discurso da interdição tem sido estrategicamente elaborado para combater os mesmos algozes de 1969: a leitura, os livros, a escola, os professores e o "novo". 
A pesquisa demonstrou que é possível transformar o isolamento em união e a tristeza em momentos de descontração, promovendo a esperança de um futuro de saúde para além da doença, podendo contribuir para o desenvolvimento de relações mais humanizadas no contexto hospitalar. Nesse espaço do imaginário, uma luva, uma máscara e os objetos do ambiente hospitalar poderão se tornar o que a imaginação das crianças e adolescentes desejarem, na promoção de uma ressignificação de objetos, situações e sonhos.

\section{Nota}

1 O Tico-Tico foi a primeira e a mais importante revista voltada para o público infanto-juvenil no Brasil. $\bigcirc$ primeiro número circulou em 11 de outubro de 1905, tendo à frente o jornalista Luís Bartolomeu de Souza e Silva. Disponível em: https://bndigital.bn.gov.br/artigos/o-tico-tico/. Acesso em: 15 nov. 2018.

\section{Referencias}

ALTHUSSER, Louis. Aparelhos ideológicos de Estado. Rio de Janeiro: Edições Graal, 1985.

20 Antonio D'Ávila. Literatura infanto-juvenil. São Paulo: Editora do Brasil, 1969.

BRIGGS, Asa; BURKE, Peter. Uma história social da mídia: de Gutenberg à Internet. Rio de Janeiro: 2004.

FERREIRO, Emília. O ingresso na escrita e nas culturas do escrito: seleção de textos de pesquisa. São Paulo: Cortez, 2013.

FIORIN, José Luiz. Argumentação. São Paulo: Contexto, 2015.

FOUCAULT, Michel. Vigiar e punir: nascimento da prisão. Petrópolis: Vozes, 2014.

GIROUX, Henry. Escola crítica e política cultural. São Paulo: Cortez, 1988.

KRESS, Gunther; VAN LEEUWEN, Theo. Multimodal discourse: the modes and media of contemporary communication. Londres: Bloomsbury, 2001.

OLIVEIRA, Fernando Rodrigues. O Ensino da literatura infantil e os novos modelos de curso de formação de professores: a consolidação de um campo de ensino, estudos e pesquisas (1971-2003). São Paulo: Editora da UNESP, 2015.

OSAKABE, Haquira. Argumentação e discurso político. São Paulo: Martins Fontes, 1999. 
PÊCHEUX, Michel. Semântica e discurso. Campinas: Editora da UNICAMP, 2009.

PÊCHEUX, Michel; ACHARD, Pierre; DAVALLON , Jean; DURAND, Jean-Lovis; Orlandi, Eni Puccinelli. Papel da memória. Campinas, SP: Pontes, 2015.

RAMA, Angela; VERGUEIRO, Waldomiro. Como usar as histórias em quadrinhos na sala de aula. São Paulo: Contexto, 2007.

RAMOS, Paulo. A leitura dos quadrinhos. São Paulo: Contexto, 2012.

WERTHAM, Frederic. Seduction of the innocent. Toronto: Rinehart, 1954.

Doutorando Felipe de Souza Costa Universidade de São Paulo (Brasil) Faculdade de Educação Programa de Pós-Graduação em Educação Grupo de Estudos e Pesquisa Produção Escrita e Psicanálise (GEPPEP) ORCID ID: https:/ / orcid.org/0000-0002-72 14-8915 E-mail: feliped_sc@usp.br Recebido 8 mar. 2019 Aceito 10 maio 2019 